\title{
A relação interpessoal entre profissionais de saúde e adolescente gestante: distanciamentos e aproximações de uma prática integral e humanizada
}

\author{
Interpersonal relations between health professional \\ and pregnant adolescents: distances and approaches \\ of integral and humanized care
}

Marta Maria Antonieta de Souza Santos ${ }^{1}$

Claudia Saunders ${ }^{2}$

Mirian Ribeiro Baião ${ }^{2}$

\footnotetext{
${ }^{1}$ Programa de Pósgraduação, Instituto de Nutrição Josué de Castro, Universidade Federal do Rio de Janeiro. Avenida Brigadeiro Trompowisky s/ $\mathrm{n}^{\circ}-\mathrm{CCS} / \mathrm{Bl}$. J/2 $2^{\circ}$ andar/sala 07, Ilha do Fundão. 21941590 - Rio de Janeiro, RJ antonietamss@globo.com

${ }^{2}$ Grupo de Pesquisa em Saúde Materna e Infantil, Núcleo de Pesquisa em Micronutrientes, Instituto de Nutrição Josué de Castro, Universidade Federal do Rio de Janeiro
}

\begin{abstract}
This study presents an analysis of relations between health professionals and pregnant adolescents in the installations of the prenatal care program of a public hospital in Rio de Janeiro. It involves qualitative research based on an interpretive approach, with comprehensiveness and humanization of care in relationship dimensions as a theoretical benchmark. Based on two predefined themes - the interaction between subjects and educational dimension of health practices 22 individual and group care sessions were observed, with the participation of 31 pregnant adolescents, 5 professionals and 2 nutrition interns. The interpretation of the data using content anal$y$ sis created five categories. The results show the negative effect of the predominance of the biomedical dimension in the perception of health professionals about psychosocial and cultural aspects of teenage pregnancy. There was a failure to utilize the care session as a privileged space for the construction of collective and individual significance about pregnancy and teenage motherhood, albeit in the context studied there are professionals who are aware of the need for a broader view regarding the needs of pregnant adolescent.
\end{abstract}

Key words Pregnancy in adolescence, Prenatal care, Qualitative research
Resumo Este estudo apresenta uma análise sobre as relações entre profissionais de saúde e adolescentes gestantes nos espaços do programa de prénatal de uma maternidade pública do município do Rio de Janeiro. Trata-se de investigação de cunho qualitativo apoiada na vertente interpretativa, tendo como referencial teórico a integralidade e a humanização do cuidado em suas dimensões relacionais. Com base em duas temáticas previamente definidas - interação entre os sujeitos e dimensão educativa das práticas em saúdeforam observados 22 atendimentos individuais e em grupo, com a participação de 31 adolescentes gestantes, 5 profissionais de saúde e 2 estagiárias de nutrição. A interpretação dos dados, orientada pela análise de conteúdo fez emergir cinco categorias. Os resultados apontam a interferência negativa da predominância da dimensão biomédica na percepção dos profissionais de saúde sobre os aspectos psicossocioculturais da gestação na adolescência. Foi observado o não aproveitamento da consulta como espaço privilegiado de construção de significados coletivos e individuais sobre a gestação e a maternidade na adolescência, mas há no contexto estudado profissionais sensibilizados para uma ampliação da visão sobre as necessidades da adolescente gestante.

Palavras-chave Gravidez na adolescência, Atenção pré-natal, Pesquisa qualitativa 


\section{Introdução}

No Brasil, a crescente demanda no cotidiano das unidades de saúde tornou a gravidez na adolescência (GA) objeto de discursos e ações, sobretudo voltadas às questões da Clínica. Entretanto, para além da dominância da clínica, a assistência pré-natal (PN) a adolescentes requer a reorientação da prática dos profissionais de saúde (PS) no sentido de reintegrar suas dimensões biomédica e interpessoal, permitindo a (re)significação dos encontros terapêuticos de modo a caracterizá-los como "cuidado". Mais do que somente competência tecnocientífica, o cuidado em saúde prescinde de aspectos não-técnicos (humanos, éticos, organizacionais, sociais, econômicos, culturais, políticos) capazes de imprimir significado prático à sua aplicação, se constituindo em espaços de escuta, diálogo e relação ética e dialógica entre os atores implicados em sua produção $0^{1-3}$.

$\mathrm{Na}$ literatura científica nacional há uma lacuna sobre a interpretação das relações estabelecidas entre PS e adolescentes gestantes (AG). Apenas duas produções ${ }^{4,5}$, ambas desenvolvidas na atenção básica e sob a perspectiva de apenas um dos sujeitos envolvidos, trazem à discussão aspectos subjetivos de sua dimensão cuidadora. Revelam que a AG espera que a atenção $\mathrm{PN}$ supra suas necessidades de esclarecimentos sobre o processo gestacional e a oriente quanto aos cuidados que lhe assegurem uma gestação saudável e um parto seguro. Espera, ainda, receber o apoio para o enfrentamento dos problemas pessoais e obter a confiança para que não seja influenciada por informações contraditórias, geralmente obtidas em seu círculo de convivência.

No debate epistemológico atual, o "tratar" tem sido reconhecido como uma prática biomédica mecanicista, autoritária e normatizadora que privilegia o agir técnico em detrimento da discussão coletiva e da comunicação, atraindo o interesse reflexivo daqueles que buscam transformálo em cuidado. É nessa perspectiva que se situa o objeto deste estudo: a relação PS-AG nas consultas de PN e em grupos de educação em saúde. Partiu-se do pressuposto de que um dos grandes dilemas enfrentados no cotidiano das maternidades, em especial as públicas, é a aplicabilidade do discurso sobre integralidade e humanização na concretude da prática dos PS envolvidos com o PN de adolescentes.

A integralidade, como um dos princípios básicos do Sistema Único de Saúde (SUS), congrega três conjuntos de sentidos: 1) transformação do agir em saúde enquanto crítica à atitude bio- médica fragmentária; 2) organização dos serviços visando à superação da dicotomia entre práticas de saúde pública e práticas assistenciais; 3 ) construção de políticas de saúde especiais voltadas a oferecer resolubilidade a um problema de saúde específico ou que afetem a determinados grupos da população. Seja com referência a qualquer um desses sentidos ou em muitos outros que o termo integralidade venha a comportar, o importante é sua fundamental oposição ao reducionismo e à objetivação dos sujeitos s $^{6}$

Também a humanização é um termo que permite diversas compreensões, oferecendo respaldo a múltiplos discursos e práticas no campo da saúde. Todavia, quer seja na relação da administração dos serviços com os PS, na relação dos PS entre si, ou, na relação dos PS com os usuários dos serviços, a humanização na saúde "significa um movimento instituinte do cuidado e da valorização da intersubjetividade nas relações", sem, contudo, relegar a competência e os avanços tecnocientíficos ${ }^{7}$.

Com base nestas reflexões, objetivou-se analisar, sob a perspectiva da integralidade e da humanização do cuidado, a relação profissional de saúde-adolescente gestante em consultas individuais e em grupo de educação em saúde do programa de pré-natal de uma maternidade pública do município do Rio de Janeiro (RJ), Brasil.

\section{Metodologia}

Trata-se de um estudo descritivo conduzido pela metodologia qualitativa, em sua vertente interpretativa. Tem como suporte teórico a integralidade e a humanização do cuidado em suas dimensões voltadas para a relação PS-AG, visando à compreensão dos significados que o agir em saúde adquire em diversas situações da assistência PN.

Para construção de dados optou-se pela utilização da técnica de observação não-participante e sistemática, considerada aquela na qual o pesquisador, com auxílio de um roteiro de observação, sabe o que procura e o que necessita ser focalizado em determinada situação para responder a propósitos previamente estabelecidos ${ }^{8}$.

O trabalho de campo foi realizado nos espaços do programa de pré-natal para AG (PPNAG) de uma maternidade pública do município do RJ, especificamente nos ambulatórios de obstetrícia e nutrição e na sala de atividades grupais. $\mathrm{O}$ estudo, realizado nos meses de Junho e Julho de 2008, foi aprovado por um Comitê de Ética em 
Pesquisa da Universidade Federal do Rio de Janeiro e consentido pela instituição cenário da pesquisa.

De acordo com os pressupostos da abordagem qualitativa, a amostra foi composta pelo critério de saturação, ou seja, pela identificação do ponto em que surgia uma constante reapresentação de elementos comuns nas situações que refletiam os objetivos da pesquisa'. Foram observadas 11 consultas de obstetrícia, 5 sessões de grupo de educação em saúde e 6 consultas de nutrição, todas voltadas para $A G$ em qualquer idade gestacional. Ao final de cada observação, situações-chave, trechos de diálogos, comportamentos e gestos registrados pela pesquisadora no caderno de campo, lhe serviram de subsídios para a produção de um relato descritivo e detalhado, em formato discursivo e dialógico expresso em forma de texto, enquanto um entrelaçamento de várias partes menores para a produção de um todo interrelacionado.

Dada a possibilidade de observação de mais de um tipo de atendimento oferecido a uma mesma AG, o estudo contou com a participação de 31 AG com idades variando entre 15 e 19 anos. Os procedimentos da pesquisa garantiram o anonimato dos participantes, identificado-os pelos códigos PS para profissional(is) de saúde e AG para adolescente(s) gestante(s).

A escolha da observação como única técnica de pesquisa foi um limite deste trabalho, mas a opção por fazê-la se justificou pela possibilidade de permitir a observação dos comportamentos e diálogos estabelecidos na relação entre os sujeitos in loco e em tempo real ${ }^{10}$.

Para análise dos dados foi utilizada a vertente temática da análise de conteúdo descrita por Bardin ${ }^{11}$ e adaptada para o estudo. Na etapa inicial ("pré-análise"), a leitura e a releitura do material empírico permitiram sua organização para posterior identificação de trechos mais significativos, a fim de compor o corpus de análise. $\mathrm{Na}$ etapa seguinte ("exploração do material"), iniciou-se o processo de categorização a partir da identificação das temáticas previamente definidas pelas pesquisadoras: (1) a interação entre os sujeitos; (2) a dimensão educativa das práticas em saúde. A identificação e a classificação dos núcleos de sentido do material empírico produzido, fizeram emergir 5 categorias que tiveram significado no contexto dos objetivos do estudo.

Por fim, na etapa interpretativa, procedeu-se a articulação do material empírico com o teórico, a fim de compreender o processo interativo PS-AG na maternidade estudada, captar os sig- nificados dessa experiência para ambos e contribuir para a transformação da prática em saúde no PN de adolescentes.

\section{Resultados e Discussão}

\section{O cenário e os sujeitos da pesquisa}

$\mathrm{O}$ estudo foi realizado numa maternidade pública do município do RJ que desenvolve atividades de ensino, pesquisa e assistência, dispondo de infraestrutura para atenção ao pré-natal, parto e puerpério de mulheres adultas e adolescentes. Estas, em geral, pertencem a categorias sociais de baixa renda e residem nas comunidades do entorno da maternidade, cujo PN prevê, especificamente para as $A G$, a participação em grupo de educação em saúde. A equipe de saúde do PN é composta por médico obstetra, nutricionista, assistente social, psicólogo, musicoterapeuta, fisioterapeuta e profissionais da enfermagem. Para a realização das consultas e dos grupos, as AG são divididas em subgrupos: as menores de 17 anos, assistidas nas manhãs de sexta-feira, e as com 17 anos ou mais, assistidas nas manhãs de quarta-feira.

\section{$O$ atendimento em grupo às adolescentes gestantes}

A atividade em grupo ocorre em uma ampla sala com cadeiras dispostas em grande círculo. Dirigida a todas as AG inscritas no PN, a atividade permite a participação de um acompanhante por gestante. A frequência é mensal e "compulsória", uma vez que as AG somente são encaminhadas às consultas individuais (de obstetrícia, nutrição e demais especialidades que demandem), após participação nessa atividade.

Sua coordenação é de responsabilidade de uma dupla de profissionais da saúde mental que se alternam na condução, algumas vezes acompanhados por um ou dois profissionais da equipe de saúde. Embora haja uma temática norteadora, as sessões têm dinâmica própria e abordagens adaptadas à demanda, grau de interesse e participação das AG, exigindo sensibilidade e flexibilidade das coordenadoras. A atividade tem a duração de 1 hora e 30 minutos.

\section{A consulta médica}

O ambulatório de obstetrícia localiza-se no andar térreo do prédio de ambulatórios da ma- 
ternidade. Neste andar, concentram-se todos os ambulatórios de gineco-obstetrícia, à exceção de um, ocupado por um enfermeiro responsável pela consulta de triagem.

Todas as AG inscritas no PN são acompanhadas por um mesmo médico obstetra, referência na unidade para gestação na adolescência. O tempo médio das consultas observadas foi de 11 minutos, com variação de 8 a 16 minutos.

\section{A consulta de nutrição}

$\mathrm{O}$ ambulatório de nutrição localiza-se no $2^{\circ}$ andar do prédio de ambulatórios da maternidade, que concentra todos os ambulatórios dos PS não-médicos, à exceção de um, ocupado por médico pediatra responsável pelas consultas de "follow-up" dos recém-nascidos prematuros.

O espaço do ambulatório é virtualmente subdividido em dois ambientes, cada qual ocupado por um nutricionista e/ou estagiário de nutrição. Frequentemente observa-se o atendimento simultâneo de AG e gestante adulta, visto não existir, sequer, uma divisória que possa, minimamente, prover privacidade aos espaços, comprometendo os princípios fundamentais de confiança, respeito e sigilo.

O acompanhamento nutricional das AG é desenvolvido por um único nutricionista, referência para o PPNAG. A média de duração das consultas observadas foi de 62 minutos, variando entre 28 a 69 minutos.

\section{A interação entre os sujeitos}

Em uma atenção integral e humanizada, espera-se que a relação entre PS e AG reflita atitudes de "encontro com o Outro", de "cuidado dialogado". Para o filósofo Martin Bubber ${ }^{12}$ é somente na relação com o Outro e, primordialmente por meio do diálogo, que o ser humano pode ser compreendido. Segundo o autor, uma autêntica relação entre seres humanos deve ser permeada não por uma interação objetivante (EU-ISSO), mas por uma interação dialógica (EU-TU), intencionalmente realizada como abertura ao Outro, a fim de estabelecer um encontro "entre-dois" (do EU e TU); ou seja, um encontro entre sujeitos na singularidade de suas subjetividades.

"Sou muito democrática, desde que façam o que eu quero": dominação e sujeição, mando e obediência

O material empírico analisado revelou a predominante permanência da verticalização na re- lação dos PS com as AG. Em seus discursos, alguns profissionais revelam débeis atitudes de estímulo às adolescentes com relação ao autocuidado na gestação. $\mathrm{O}$ recorte selecionado abaixo retrata uma dessas situações, cuja ênfase dada pelo PS em sua fala demonstra a clara manifestação de poder e imposição, legados do tradicional e hegemônico paradigma biomédico, que, consciente ou inconscientemente, ainda resiste em discursos e práticas de saúde.

"Eu [a PS] falo mesmo pra elas [as AG]: Sou muito democrática, desde que façam o que eu quero! [e riu]. Os pais deveriam orientá-las antes [de engavidarem], dar colo antes. Querem passar a mão na cabeça e dar colo agora. Agora, não. Tudo bem, não vamos [os PS] forçá-las a assumir uma responsabilidade exagerada, como a dos adultos, mas, a responsabilidade com o se cuidar, com a gravidez, é delas. $\mathrm{E}$ isso a gente tem que estimular!"

(caderno de campo - observação do atendimento - grifos das autoras)

Importa aqui a reflexão sobre o tipo de responsabilidade a que se refere o PS. Embora motivado pelo propósito de orientar, o faz por meio de um discurso autoritário e autorreferente. Passando a julgar as AG e seus familiares a partir de sua ótica, estabelece unilateralmente o que é certo ou errado, adequado ou inadequado em relação ao cuidado à saúde, colocando-se como aquele que sabe mais sobre o outro do que ele mesmo. Esse raciocínio tradicional da biomedicina produz intervenções cuja pretensão é a de oferecer ao usuário uma autonomia consentida, tutelada, mantendo-a sob controle e cobrando desse usuário a responsabilidade, mas, da forma como a concebe. Assim, a autonomia passa ao largo de uma conquista negociada e dialógica que oportunize ao usuário manifestar-se, refletir sobre o que é dito e o que pensa sobre isso, a fim de possibilitar sua participação nas decisões.

Segundo Merhy ${ }^{13}$ conceitos muitas vezes presentes no discurso de PS não se encontram refletidos no cotidiano de suas práticas e posições culturais e político- ideológicas, ainda que de forma não intencional. $\mathrm{O}$ autor se refere especialmente à integralidade, categoria cujos significados convergem para profundas mudanças nas ações em saúde, mas, que tem sido utilizada por muitos apenas para revestir modelos "bem tradicionais, bem corporativo-centrados" de produção do cuidado em saúde. Em uma dada consulta, foi possível observar conflito no agir de um $\mathrm{PS}$ ao indagar à $\mathrm{AG}$ se tinha "alguma dúvida ou se já sabia tudo". Como a AG o respondeu 
que não tinha nenhuma dúvida, o PS (aumentando seu tom de voz, com o pescoço projetado para frente e mantendo as sobrancelhas levantadas) a interpelou:

PS: "Como não? Senão, você não teria ganhado 20 quilos! Faz tempo que não passamos na nutrição, né? Quando passava, já não dava certo, que dirá agora, né? Tú tá fazendo tudo o que a nutricionista falou?"

AG: "Tồ!"

PS: "Tá como?"

(caderno de campo - observação do atendimento - grifos das autoras)

Pondo-se em xeque a competência da AG para o autocuidado, dificulta-se o estímulo à corresponsabilidade desta com a própria gravidez. A entonação e expressão facial alteradas e o uso de perguntas "ameaçadoras", do tipo "como não?", evidenciou o domínio da PS na relação. É fundamental que os PS compreendam que é a maneira como a AG percebe a relação que determina, em grande parte, a natureza de sua resposta. Assim, quando se vê forçada a dar uma explicação sobre uma questão não muito clara para ela, lança mão de respostas dissimuladas ou defensivas.

Embora não seja objetivo deste texto fazer um exame aprofundado sobre a formação dos PS, importa destacar o quanto a influência do modelo biomédico sobre a organização de currículos e conteúdos dos cursos na área da saúde tem contribuído para a formação de profissionais cujas competências e habilidades não mais correspondem às expectativas da sociedade. Segundo Merhy ${ }^{13}$, para atuar, o PS necessita dispor de três tipos de "caixas de ferramentas tecnológicas", as quais denomina: "valise da mão", constituída pelas "tecnologias duras", representadas por equipamentos/máquinas; "valise da cabeça", composta por "tecnologias leve-duras", referentes aos saberes profissionais bem estruturados; e, por fim, "valise das relações", contendo "tecnologias leves", implicadas na produção do "trabalho vivo em ato", que só se realiza no espaço relacional entre dois sujeitos - PS e usuário. Sob o referencial das tecnologias em saúde do referido autor ${ }^{13}$, a formação não promove a articulação entre os conhecimentos tecnocientíficos e o desenvolvimento de habilidades de comunicação com o outro, produzindo um "empobrecimento da valise das tecnologias leves", modelando o perfil tecnoassistencial dos PS.

É diante da singularidade das realidades dos usuários que cada PS é levado a compreender as limitações de sua possibilidade de atuação e, consequentemente, a rever as relações de poder que estabelece na interação que mantém com usuários e com outros profissionais. Contudo, nem sempre o PS se "curva" às demandas dos usuários. Em uma consulta, ante a dúvida da AG sobre a opinião de sua mãe quanto à posição para dormir, a PS questionou o motivo de tal opinião e, sem mesmo aguardar a resposta, antecipou-se em reprovar o comportamento da AG e em reafirmar sua posição enquanto detentora do saber:

AG: "Eu posso dormir de bruços? A minha mãe falou que não pode. Aí eu dormi até sentada".

PS: "E, por quê? Pra todo mundo ficar com pena de você? Você acha que se não pudesse, a gente aqui não teria dito isso a você?"

(caderno de campo - observação do atendimento - grifos das autoras)

A racionalidade biomédica interfere negativamente na percepção dos PS sobre os aspectos sociais e culturais da gravidez. A postura da PS diante da AG revela sua indisponibilidade para estar totalmente "com ela" no encontro do cuidado. No âmbito da dimensão humana do cuidado em saúde, atitudes como essa têm um poder determinativo, senão coercitivo, no diálogo. Ao dominar o diálogo e expressar perplexidades e anulação do saber popular, a PS perde a oportunidade de valorizar e de buscar, na riqueza da relação dialógica, as representações que constroem o discurso do outro ${ }^{14}$.

No pensamento buberiano ${ }^{12}$, ao estabelecer contato com o diferente, a convicção do ser humano de seus próprios valores o leva a revestirse de um "poder moral" capaz de transformar a relação "EU-TU" em "EU-ISSO". É quando, em função do estranhamento, o "eu" reifica o "outro" e anula-o como sujeito.

Todas as atividades do PPNGA observadas tiveram seu início marcado pela tentativa dos profissionais em estabelecer uma relação empática com as AG. Apesar disso, nem todas as relações seguiram o curso de uma autêntica escuta interessada, obstaculizando o diálogo e promovendo a evidente emergência de problemas:

“(...) A gestante disse [à PS] que o bebê estava se mexendo muito e que ela não conseguia dormir. A profissional, então, a respondeu: 'Você vai dormir e deixa ele se mexendo!'. A gestante sorriu e falou: 'Ah, não consigo'. (...) a gestante perguntou: 'Qual o tamanho do bebê?' A profissional a respondeu: 'É impossível saber por que ele fica todo encolhido'. (A PS) Perguntou se a gestante tinha mais alguma dúvida. Ela (um pouco constrangida) disse que não."

(caderno de campo - observação do atendimento - grifos das autoras) 
Atitudes assim, "fechadas" ao diálogo, funcionam como travas à motivação e à iniciativa da AG, que busca minimizar as inquietações próprias da gestação por meio da compreensão dos delicados processos corporais que cursam neste período. Estudos ${ }^{15-19}$ pautados nos princípios da integralidade e da humanização e comprometidos com a melhoria da qualidade da assistência à saúde demonstram a frequente observação de PS tecnicamente eficientes, mas, indiferentes e distantes, quando não ríspidos e impacientes, nas relações com os usuários. A mulher durante o período da gestação, em especial a adolescente, vivencia momentos de medos, dúvidas e preocupações que a fazem buscar o apoio de alguém, não só tecnicamente capacitado para uma abordagem clínica, mas que também seja sensível à escuta e ao diálogo, a fim de que se sinta acolhida. Segundo Buber ${ }^{12}$, para além do sentido ético e moral, a responsabilidade do profissional no âmbito do cuidado em saúde deve ser entendida como habilidade de saber dar respostas.

$\mathrm{O}$ uso de linguagem não apropriada foi observado em comentários tecidos por PS, que, mesmo sem a intencionalidade, são passíveis de desencadear sentimentos de constrangimento e vergonha na gestante, especialmente quando esta é adolescente:

“(...) a profissional perguntou ao pai [do bebê] o que queria saber sobre o filho, e complementou: Além de costurar a boca dela [da AG] para parar de comer!"

(caderno de campo - observação do atendimento - grifos das autoras)

Procedimentos como este, tendem a retrair as AG e, em consequência, podem deflagrar dificuldades para se expressarem no âmbito interpessoal, estabelecendo-se uma relação monológica, na qual a fala da $A G$ poderá praticamente se restringir à complementação do discurso do profissional. Para que as relações PS-AG sejam positivas, necessariamente devem ser permeadas pela comunicabilidade, intersubjetividade e, fundamentalmente, pela alteridade, - que, segundo o filósofo Emmanuel Lévinas (citado por Rolando) ${ }^{20}$ é a ética da subjetividade que fundamenta a possibilidade do sujeito ser sujeito; isto é, a capacidade de as pessoas se importarem com os outros.

\section{"Queixas? Reclamações? Dúvidas? \\ Perguntas? Nada?": obstáculos à participação da gestante}

A produção de sujeitos autônomos e corresponsáveis, isto é, partícipes nos projetos terapêuticos de produção de saúde, é condição fun- damental para o processo de reorientação da organização e de práticas em saúde. Nesta direção, as discussões atuais no campo da ética biomédica apontam a indissociabilidade entre a produção de saúde e a produção de subjetividades.

Contraditoriamente, observou-se neste estudo que, em geral no nível individual da assistência, os PS percebem as AG como portadoras de atitudes e comportamentos inadequados, carentes de informação e necessitadas de um conjunto de regras e normas que as direcionem para a correção de seus hábitos de vida, visando à evolução saudável da gestação. Nesses casos, o fenômeno biológico da gestação toma o lugar da gestante como o elemento estruturante da atenção, oferecendo à consulta um caráter prescritivo e incompetente para atuar na multidimensionalidade do ser adolescente gestante ${ }^{21}$.

Durante uma consulta o PS imputa à falta de cooperação da $A G$, o fato da não adesão à dieta prescrita, empobrecendo sua análise ao desconsiderar os aspectos subjetivos que poderiam contribuir para a compreensão do problema:

PS: "Você está conseguindo seguir a dieta?"

AG: "Estou comendo muito porque estou ansiosa. Porque é a primeira vez que passo por isso [pela gravidez] e tenho sonhado muito. Estou com muito medo".

PS: "Então você tem consciência que tá fazendo errado! (...) Sua dieta já foi calculada e, se você quiser, fará tudo certo".

(caderno de campo - observação do atendimento - grifos das autoras)

Embora a AG tenha informado que estava "comendo muito" e identificado como motivo o fato de estar "ansiosa", por se tratar de sua primeira gestação, o PS não valorizou suas considerações. Ao contrário disso, passou a dialogar com a conduta alimentar esquecendo-se da adolescente, ou seja, do sujeito que confere concretização a essa conduta. Dessa forma, uma vez percebido pela AG que o PS desconsidera suas inquietações e limita-se a culpabilizá-la, a possibilidade de vínculo é fortemente ameaçada ${ }^{22}$.

$O$ interesse das AG em conhecer mais sobre sua gestação nem sempre é aproveitado pelos profissionais para o desenvolvimento da autonomia dessas jovens. Por meio da formulação de perguntas em série, após as quais ele mesmo antecipa a resposta negativa, o PS desestimula a narrativa da $A G$ e encerra qualquer possibilidade de construção de uma ação dialógica. No caso de uma consulta integral, o PS estaria empenhado numa abordagem que permitisse à AG sentirse livre para expor suas necessidades ${ }^{23}$. 
Apesar de a timidez atrapalhar a participação de algumas AG durante as consultas, a posição passiva por elas assumida ocorre, sobretudo, em consequência do grau de assimetria instalado, modulado pelo maior ou menor espaço oferecido pelos PS para a conversa e a escuta. Em algumas das situações observadas o máximo que as AG faziam era esboçar movimentos corporais, balançando a cabeça afirmativa ou negativamente, não conseguindo verbalizar suas dúvidas. Além disso, as interrupções, o tempo de duração (muito breves ou muito longas) e a falta de privacidade das consultas, também colaboraram para que as $A G$ tivessem dificuldades para assumirem sua posição de sujeitos. Neste enfoque, profissionalcentrado, a consulta é reduzida a uma intervenção mecânica, técnica e, portanto, descolada das características singulares das AG.

A orientação profissional frequentemente recomendou a adoção de substituições, reduções e proibições de alimentos consumidos pelas AG. Porém, essa prática tendeu a desconsiderar os possíveis sentidos desses alimentos para a AG, sentidos estes socioculturalmente construídos e compartilhados em sua família. Segundo Baião e Deslandes ${ }^{24}$ há uma sincronia entre as alterações no comportamento alimentar da gestante e o significado que esta atribui à sua própria gravidez. Dessa forma, as autoras chamam a atenção para a importância do reconhecimento dos diferentes significados que permeiam a gestação, em favor da construção de encontros dialógicos, criativos e, acima de tudo, éticos, "que possam resultar, sempre que necessário, em sua (re)significação e na tomada de decisões autônomas, o que certamente irá contribuir com melhores resultados no ciclo gravídico-puerperal".

A avaliação do ganho de peso das AG pelos PS foi um procedimento sistematicamente realizado, tendo sido o aumento de peso excessivo, uma constante preocupação demonstrada por todos. Tal preocupação relaciona-se com a associação entre aumento exagerado de peso na gestação e riscos para a saúde da mulher e do feto ${ }^{25}$.

Os excertos abaixo ilustram a percepção coletiva dos PS:

"Você ganhou mais de 180 gramas do esperado por semana. Vamos controlar o besteirol, senão vai ficar gordinha!"

(caderno de campo - observação do atendimento)

"Vocês duas [AG] ganharam muito peso. (...) Quem passou pela nutricionista? (...) O excesso de peso pode trazer riscos para a gestação. A eclampsia, vocês sabem o que é? (...) quando se ganha muito peso, a gordura pesa sobre as veias e faz aumentar a pressão (arterial)" (caderno de campo - observação do atendimento)

Segundo Martins ${ }^{26}$, o PS positivista e cientificista, em geral, se coloca na posição de "guardião da verdade" e percebe a AG como aquela "pecadora" que precisa ter seus erros corrigidos por ele, que "supostamente sabe a verdade sobre (e para) o seu corpo". O autor destaca, ainda, que essa prática se apresenta com maior clareza em unidades públicas de saúde "e junto a uma população de baixa renda", que, na maioria das vezes, por se tratar de um grupo de pessoas sem "estudo superior", é considerado não capaz de partilhar da mesma "cultura" dos PS. Contudo, considera que esse conflito entre códigos culturais também seja encontrado no âmbito da classe média.

Foram observadas situações nas quais uma relação de negociação foi estabelecida entre PS e AG. Contudo, despertou interesse que o tema recorrente nas negociações esteve particularmente relacionado a "mudanças nos hábitos alimentares" das AG. Na consulta de uma AG de 18 anos, a PS constatou, durante a anamnese, que seu consumo de legumes e frutas era insuficiente, e, ao final desta, a AG foi informada que deveria aumentar o consumo diário desses alimentos. Não possuindo o hábito de comer legumes, a AG perguntou à PS se podia "comer só um legume ou uma verdura de cada vez, ao invés de colocar muitos". A PS comentou que ia "ficar muito monótono" e que "o importante é variar". E ofereceu algumas sugestões como começar a consumi-los "na forma de sopa, depois passar a refogar, até chegar a comer na forma de salada".

Autores $^{3,24,25}$ apontam que, durante a gestação, a mulher está mais susceptível à adesão a regras de alimentação, com vistas a contribuir para a manutenção de sua saúde e de seu bebê. Todavia, com gestantes adolescentes, nem sempre essa relação é verdadeira. A conjunção de diversos fatores intimamente associados ao consumo alimentar, tanto àqueles inerentes a qualquer ser humano (fatores socioeconômicos e culturais) como os especialmente comuns entre adolescentes (estilo de vida e hábitos alimentares, como signos de pertencimento ao seu grupo social), exige do PS habilidade, sensibilidade, criatividade e intuição para a "negociação" durante $o$ aconselhamento nutricional.

É consensual o fato de o sucesso de uma intervenção em saúde estar condicionado à adesão do usuário às orientações e recomendações do profissional. Todavia, cabe a este último saber lidar com a autonomia da AG, ou seja, com sua 
liberdade no processo decisório de adesão. As preferências alimentares não estão ancoradas apenas na dimensão racional do ser humano. Esta, certamente, convive em constante tensão com as dimensões culturais e simbólicas presentes no fenômeno do consumo alimentar. Segundo Câmara Cascudo ${ }^{27}$, "a escolha de nossos alimentos diários está intimamente ligada a um complexo cultural inflexível. O nosso menu está sujeito a fronteiras intransponíveis, riscadas pelo costume de milênios". Dessa forma, o acesso a informações científicas não é o suficiente para a mudança de hábitos alimentares, cabendo aos PS a utilização de estratégias que considerem o sentido que a intervenção tem para a vida daquele usuário, com base no conhecimento das adversidades e das situações positivas por ele experienciadas, a fim de livremente envolvê-lo com a corresponsabilidade da intervenção.

\section{"Eu nem tô gorda!":}

\section{percepção do corpo frente às regras}

Contrapondo-se à perspectiva biomédica, $\mathrm{e}$ geralmente não identificada pelos PS, a percepção das AG sobre o ganho de peso na gravidez se revela não enquanto risco, mas como consequência esperada e aceita durante este período. Em algumas situações, embora a PS diagnosticasse um ganho de peso indesejado, a AG não partilhava dessa opinião, demonstrando o uso de outra lógica, que não a da biomedicina, para avaliar o seu peso corporal.

PS: "De 3 em 3 quilos não dá, né?"

AG: "Mas, eu nem tô gorda!"

PS: "Não é esse o problema. O pior são as consequências (para a saúde)".

Assim como evidenciado em outros estudos brasileiros ${ }^{28,29}$, as gestantes inseridas em baixas camadas sociais, sejam adultas ou adolescentes, não têm tanta preocupação com o "ganho excessivo de peso" como um risco à sua saúde e, tampouco, por valores estéticos extremos, como poderia significar para gestantes de camadas socioeconomicamente mais favorecidas. Menezes e Domingues $^{29}$ sugerem que, ao contrário disso e, particularmente por parte das gestantes primíparas, a identificação do "crescimento da barriga" como a mais agradável mudança corporal e as "atitudes positivas em relação ao ganho de peso" estejam associadas a um ganho de status de mãe e de mulher na sociedade. No presente estudo, as narrativas das AG demonstram preocupação com a possibilidade de "o bebê nascer de baixo peso". Uma delas comentou que ao exame de ultra-sonografia, realizada na 20a semana de gestação, o peso de seu bebê foi estimado em "quatrocentas e poucas gramas", mas, que queria ter um filho "com três quilos e setecentas [gramas] a quatro quilos". Ao ser indagada pela PS por que "fazer esse esforço tão grande, se pode [o bebê] crescer fora da barriga", a AG a respondeu: "Sei lá, acho que bebê grandão é tão bonitão! (...) É bonito bebê todo fofinho!”.

Baião e Deslandes ${ }^{24}$, em seu estudo sobre comportamento alimentar na gravidez, observaram esse mesmo sentido, especialmente relacionado a mudanças na ingestão alimentar das gestantes, pois identificaram a automotivação para aumento do consumo após a revelação do peso do bebê pela ultrassonografia.

Embora partindo de racionalidades diferentes das lógicas biomédicas e muitas vezes desprezadas pelos PS, as AG também se revelam atentas e preocupadas com possíveis influências na gestação que podem prejudicar o ganho de peso do bebê. O desejo de todas é de protagonizar uma experiência mágica em dar à luz a um bebê fantasioso, dotado de beleza e perfeição.

É possível perceber que a autonomia da gestante no cuidado com a gravidez pode ser demonstrada por formas outras, que não a adesão à prescrição e orientação dos PS. Contudo, de uma forma geral, essa autonomia não subordinada à racionalidade biomédica, se percebida, não é valorizada pelos PS. Estes, sem disposição para compreender as lógicas populares e ceder à negociação, negam o que não pode ser biologizado e acabam por comprometer a integralidade da ação em saúde.

\section{"Vida de nutricionista deve ser muito chata": crítica em sinal de resistência às normas}

Em resposta ao privilégio conferido à tecnociência em detrimento de suas singulares histórias de vida alimentar, as AG estudadas ofereceram resistência, desafiando o conhecimento, questionando normas e regras e criticando valores instituídos pelos PS. Em uma anamnese alimentar, a estagiária perguntou à $\mathrm{AG}$ sobre as quantidades dos alimentos que consumia e obteve como resposta: "Não sei. Nunca prestei atenção nisso (...) vocês são muito detalhistas (...) vida de nutricionista deve ser muito chata". A expressão desses legítimos sentimentos revela duas interessantes perspectivas da AG como sujeito da ação de saúde: indignação (por se perceber alvo de um pensamento lógico que faz uso de um extenso interrogatório para invadir sua intimidade alimentar e recomendar hábitos e comportamentos supos- 
tamente capazes de evitar riscos à sua gravidez) e compaixão (pelo profissional, que considera "convertido" às regras e renúncias alimentares propostas em seu próprio discurso, a fazendo supor o quão enfadonha deve ser sua vida).

No decorrer das consultas foi observada predominância de atos prescritivos que valorizam apenas questões biológicas, especialmente com respeito à ingestão alimentar da AG. Expressões como "se controlar", "erros alimentares", "força de vontade", "se segurar", "fechar a boca", "seguir a dieta", presentes nas falas dos PS, demonstram o quanto a biomedicina assume o papel de definidora de padrões e comportamentos alimentares das AG. E, como estratégia de impulsão da adesão às prescrições, os PS as intimidam com alusões ao conhecimento científico que dispõem sobre um dos maiores, senão o maior, de seus medos: a "hora do parto". Para isso, fazem uso de comentários sobre dificuldades no trabalho de parto de fetos macrossômicos: "Quem vai fazer força? Não sou eu. Aí, na hora [do parto], não adianta chorar e falar: 'Ai meu Deus! Por que fui comer demais e fazer com que o bebê engordasse tanto?' Então, se liga!" (caderno de campo - observação do atendimento).

Barreiras comunicacionais, como o uso de jargões biomédicos, foram também identificadas como importantes obstáculos à interação, demonstrando quanto o tecnicismo desfavorece a humanização da assistência. Em uma consulta, enquanto a estagiária conferia junto à nutricionista o cálculo do ganho de peso e do "VET" (valor energético total) da dieta a ser prescrita, a AG, que ouvia atentamente o diálogo, perguntou: "Ela tá falando grego é?”. Essa crítica sinaliza a resistência de um sujeito que recrimina o uso da linguagem técnica, cujo formato distanciado e despersonalizado a coloca em uma posição desconfortável na relação. Essa AG reclama, tão somente, de uma conversa aberta e clara que a ofereça os recursos que necessita para o fortalecimento de suas potencialidades e capacidades para participar e decidir livremente sobre a sua gravidez e a sua vida. De um modo geral, situações como esta são consequentes à limitada habilidade dos PS em escutar, respeitar e considerar o saber singular e específico que a AG traz consigo, a partir do qual, certamente, sua ação ganhará sentido para ela.

\section{A dimensão educativa das práticas em saúde}

Partindo-se do pressuposto humanístico de Paulo Freire ${ }^{30}$ de que a educação é um processo dialógico-dialético no qual todos ensinam e todos aprendem, as relações que se estabelecem entre profissionais de saúde e usuários dos serviços, são relações pedagógicas. Neste sentido, o $\mathrm{PN}$ apresenta-se como um campo propício ao desenvolvimento da educação como dimensão do processo de cuidar.

Inquestionavelmente, a relação baseada no modelo clássico, autoritário, vertical, no qual as relações entre PS e usuário são caracteristicamente relações de dominação e obediência, necessitam ser superadas pela lógica dialética da horizontalidade. Esta pressupõe o despojamento de préconceitos e pré-julgamentos e o melhor uso das tecnologias leves - como a comunicação - a fim de permitir o estabelecimento de uma abordagem humanizada na atenção PN a adolescentes. A assistência humanizada possibilita uma convivência mais próxima entre PS e AG, permitindo a troca de experiências, a solução de conflitos e o conhecimento da limitação do outro, seja por meio de linguagem verbal ou não.

"Dar o que quiser para o bebê comer é possível, mas, é o melhor?":

a construção mútua do conhecimento

Na perspectiva hermenêutica, tanto o usuário como o PS, são sujeitos das ações de saúde e portadores de experiências práticas e saberes tecnocientíficos diversos, cujas assimetrias devem ser minimizadas nas verdadeiras trocas dialógicas ${ }^{1}$. No pensamento freireano ${ }^{30}$, os sujeitos se encontram "para transformação do mundo em co-laboração”. Nesse sentido, um encontro dialógico-dialético na atenção à saúde se traduz em uma ação humanizadora, aberta à subjetivação, à contradição e à possibilidade de síntese entre as diferentes posições dos interlocutores, efetivando-se numa atenção que privilegia a ética, a ampliação do processo comunicacional e a negociação dos sentidos e rumos da produção de cuidados em saúde ${ }^{31}$.

Observou-se, neste estudo, que há situações em que os profissionais estabelecem uma relação humanizada com as adolescentes, resultando em um momento de valorização destas como seres integrais. Uma AG, provavelmente por sentir-se acolhida e confiante para expor seus sentimentos junto à PS, resolveu declarar que estava muito triste. Tendo sido perguntado o motivo, alegou que o pai de seu bebê havia discutido e terminado a relação com ela. A PS, sensível àquela colocação, voltou sua atenção ao diálogo com a AG de forma solidária:

"E a sua mãe [da AG], o que ela acha disso?" A gestante respondeu: "A minha mãe é a única 
que me dá força, me apóia. Quando eu acordo, ela me dá bom dia, me dá um beijo". A profissional disse: "Por que você não dividiu isso conosco? Você sabe que pode contar conosco". A profissional perguntou: "Você acha que ele [o pai do bebê] te enganou?" A gestante respondeu: "Não. Eu tava muito envolvida e não vi. Acho que ele me enganou um pouco, porque ele não era assim antes". A profissional falou: "Você não está sozinha, a maternidade tá do seu lado".

(caderno de campo - observação do atendimento - grifos das autoras)

Embora ocorrendo em meio a uma atividade coletiva, a implementação de um diálogo aberto e uma escuta interessada entre PS e AG favoreceu a efetivação dessa relação como um momento de atenção personalizada, pois permitiu a expressão de emoções referentes ao período gestacional da adolescente, de modo que estas fossem acolhidas e ressignificadas. De acordo com Schraiber ${ }^{32}$, o êxito de um profissional não se sustenta somente pelas condições materiais, ou quiçá apenas por sua competência tecnocientífica. São também necessários os dispositivos relacionais (acolhimento, vínculo, resolubilidade e responsabilização), como uma malha de atitudes e comportamentos que geram sentidos que podem instituir um novo agir em saúde, tendo como referencial a integralidade. Todavia, é importante destacar o "fio da navalha" em que se coloca a conduta assumida pelo PS na situação acima retratada, pois uma vez oferecido apoio institucional à $\mathrm{AG}$, esta poderá percebê-lo de outra forma que não a mesma que motivou a PS a fazê-lo. A percepção de cada um sobre uma situação ou um problema está essencialmente relacionada à sua possibilidade de percebê-lo. Dessa forma, a AG poderá ampliar seu horizonte de expectativa por meio de significações distintas daquelas que o PS pretende com sua conduta.

Durante a atividade em grupo realizada junto às $A G$, foi possível observar esforços dos PS, particularmente da saúde mental, empenhados na promoção de uma assistência humanizada, traduzida pela realização de ações de educação em saúde em favor da produção do conhecimento das AG sobre a gestação e a maternidade. Foi interessante constatar que a observação de algumas das ações praticadas por esses PS revelou formas de atuação promotoras da interdisciplinaridade, na direção da integralidade da atenção à saúde das AG. Por meio de abordagens humanistas, para as quais o significado e a singularidade dos fatos importam mais do que os fatos propriamente ditos, a relação pedagógica se dá em um clima favorável ao empoderamento da AG. Dessa forma, a atividade se revelou um espaço pedagógico horizontalizado, capaz de potencializar práticas educativas que conduzem à reflexão sobre vivências da adolescência, da sexualidade, da gestação e da maternidade.

PS: "Quem aqui vai amamentar?"

AG (de 15 anos): "Eu vou, mas só até os 3 meses. Porque aí..., já vou dar o suquinho e, aos 5 meses, a papinha".

PS: "Por quê?"

AG: "Ah, porque minha mãe fez assim comigo e, eu tô viva até hoje".

PS: "Dar o que quiser para o bebê comer é possível, mas, é o melhor?"

Todas (as AG) responderam que não. A profissional, então, passou a explicar as vantagens do leite materno. E todas (as $A G$ ) prestaram bastante atenção.

(caderno de campo - observação da atividade coletiva - grifos das autoras)

Por meio de uma "pergunta disparadora" apresentada pelo PS ao grupo de AG, foi possível estimular a participação do grupo e a narrativa contextualizada de uma das AG. A partir do compartilhamento de saberes tácitos, teóricos e técnicos é possível a reavaliação de crenças e a revisão de valores, nos quais encontram-se ancoradas as atitudes e as posições assumidas pelos PS e pelas AG. Nesta perspectiva, a estratégia pode ser compreendida como uma ferramenta dialógica entre os conhecimentos tácitos e tecnocientíficos que, avançando para além das prescrições técnicas do que é bom ou mau, do que é certo ou errado, permite o alcance de escolhas refletidas.

As atividades grupais de educação em saúde observadas demonstraram se tratar de uma estratégia facilitadora da expressão das necessidades, expectativas, angústias e circunstâncias de vida, que tem algum impacto na evolução da gestação das adolescentes estudadas. A comunicação estabelecida proporciona a interação e o diálogo necessários para a construção de relacionamentos, sentidos e significados compartilhados, resultando em comprometimento, participação e emancipação dos sujeitos envolvidos. A promoção de reflexões voltadas para a construção, relacionada às significações e ressignificações das experiências de gravidez e à noção de responsabilidade das AG permite torná-las sujeitos do processo de cuidado de si e de seu filho. A grande riqueza dessa prática é promover a tomada de decisões "conscientes" pelas AG.

Ações educativas em saúde, desenvolvidas em contextos coletivos e com a participação de indi- 


\section{Considerações finais}

O estudo revela importantes questões quanto ao modo do profissional de saúde se relacionar com a AG. Tomando o conjunto dos resultados obtidos, percebeu-se a predominância da dimensão biomédica nas consultas observadas. Tal predomínio interferiu negativamente na percepção dos profissionais, inicialmente centrada na gestação e não nas necessidades de saúde da AG. Orientações marcadamente técnicas caracterizaram grande parte da abordagem dos profissionais, os induzindo ao não aproveitamento da consulta como espaço privilegiado de educação em saúde e de construção de significados coletivos e individuais sobre a gestação e a maternidade na adolescência.

Apesar de a maioria dos profissionais de saúde não valorizar aspectos psicossocioculturais presentes nas narrativas das adolescentes, foi possível identificar aproximações a uma abordagem integral e humanizada. Estas, praticadas por profissionais da saúde mental em atividades grupais junto às $A G$, se distinguiam do modelo hegemônico da biomedicina pela presença ativa dos sujeitos nas trocas dialógicas e pela produção e desenvolvimento da autonomia das AG.

Acredita-se que o estudo possa contribuir para a reflexão sobre a importância de uma formação profissional voltada para o desenvolvimento de competências técnicas e relacionais, forjadas sob princípios ético-humanísticos e capazes de transformar as pessoas em sua prática cotidiana, desde que para isso haja, também, disponibilidade interna do profissional e espaços para colaboração interpessoal nos serviços. Isso significa dizer que a ainda hegemônica abordagem biologicista, medicalizante e procedimento-centrada, presente na formação acadêmica dos profissionais da área da saúde, precisa, urgentemente, ser rompida para dar lugar a processos educativos que possibilitem a articulação de conteúdos e de campos disciplinares distintos, promovendo práticas profissionais organizadas a partir das necessidades de saúde da população. É necessário, portanto, que no âmbito das universidades, haja simultaneidade da formação tecnocientífica com o uso de tecnologias capazes de instrumentalizar o futuro profissional para o autoconhecimento, a comunicação e o relacionamento interpessoal, ampliando as possibilidades de torná-lo mais comprometido e responsável com o cuidar em saúde de forma mais humanizada, sistêmica e integradora.

Contudo, isso só não basta, pois implica, também, na implementação de estratégias que promovam a organização do trabalho nos serviços de saúde, de modo a viabilizar a construção de uma lógica diferenciada de atenção. Lógica esta, voltada ao atendimento das necessidades dos usuários e pautada na integração e no diálogo entre os diferentes sujeitos envolvidos no processo de trabalho em saúde.

\section{Colaboradores}

MMAS Santos, C Saunders e MR Baião participaram igualmente de todas as etapas de elaboração do artigo. 


\section{Referências}

1. Ayres JRCM. Da necessidade de uma prática reflexiva sobre o Cuidado: a hermenêutica como acesso ao sentido das práticas de saúde. In: Pinheiro R, Mattos RA, organizadores. Razões públicas para a integralidade em saúde: o cuidado como valor. Rio de Janeiro: Instituto de Medicina Social (IMS), Universidade do Estado do Rio de Janeiro (UERJ), Abrasco; 2009. p. 127-144.

2. Deslandes SF, organizadora. Humanização dos cuidados em saúde: conceitos, dilemas e práticas. Rio de Janeiro: Editora Fiocruz; 2006.

3. Helman CG. Cultura, saúde e doença. Porto Alegre: Artes Médicas; 2003.

4. Araújo R. Sentimentos, significados e aprendizagens de adolescentes grávidas cadastradas em serviços de pré-natal: buscando subsídios para a integralidade das ações [dissertação]. Jequié (BA): Universidade Estadual do Sudoeste da Bahia; 1999.

5. Melo MCP, Coelho EAC. Integralidade e cuidado a grávidas adolescentes na atenção básica. Cien Saude Colet 2011; 16(5):2549-2558.

6. Mattos RA. Os sentidos da integralidade - algumas reflexões acerca de valores que merecem ser defendidos. In: Pinheiro R, Mattos RA, organizadores. Os sentidos da integralidade na atenção e no cuidado à saúde. Rio de Janeiro: IMS - UERJ, Abrasco; 2001. p. 39-64.

7. Minayo MCS. Sobre Humanismo e Humanização. In: Deslandes SF, organizadora. Humanização dos cuidados em saúde: conceitos, dilemas e práticas. Rio de Janeiro: Editora Fiocruz; 2006. v. 1, p. 23-30.

8. Marconi MA, Lakatos EM. Fundamentos da metodologia cientifica. 5a ed. São Paulo: Atlas; 2003.

9. Minayo MCS. O desafio do conhecimento: pesquisa qualitativa em saúde. São Paulo, Rio de Janeiro: Editora Hucitec, Abrasco; 2007.

10. Pope C, Mays N. Pesquisa qualitativa na atenção à saúde. $3^{\text {a }}$ ed. Porto Alegre: Artmed; 2009.

11. Bardin L. Análise de conteúdo. Lisboa: Edições 70; 2008.

12. Bubber M. Eu e tu. Trad. Newton Aquiles von $\mathrm{Zu}-$ ben. São Paulo: Centauro; 2001.

13. Merhy EE. Engravidando palavras: o caso da integralidade. In: Pinheiro R, Mattos RA, organizadores. Construção social da demanda. Rio de Janeiro: Instituto de Medicina Social (IMS), Universidade do Estado do Rio de Janeiro (UERJ), Centro de Estudo e Pesquisa em Saúde Coletiva (Cepesc), Abrasco; 2005. p. 195-206.

14. Ayres JRCM. Cuidado: tecnologia ou sabedoria prática. Interface Comun Saúde Educ 2000; 4(6):117-112.

15. Caprara A, Franco ALS. A Relação paciente-médico: para uma humanização da prática médica. Cad Saude Publica 1999; 15(3):647-654.

16. Caprara A, Rodrigues J. A relação assimétrica médico-paciente: repensando o vínculo terapêutico. Cien Saude Colet 2004; 9(1):139-146.

17. Duraes-Pereira MBBB, Novo NF, Armond JE. A escuta e o diálogo na assistência ao pré-natal, na periferia da zona Sul, no município de São Paulo. Cien Saude Colet 2007; 12(2):465-476.
18. Heil Silva CMGC, Rodrigues CHS, Lima JC, Jucá NBH, Augusto KL, Lino CA, Carvalho AGN, Andrade FC, Rodrigues JV, Caprara A. Relação médico-paciente em oncologia: medos, angústias, habilidades comunicacionais de médicos na cidade de Fortaleza, Ceará, Brasil. Cien Saude Colet 2011; 16(Supl. 1):1457-1465.

19. Rossi PS, Batista NA. The teaching of communication skills in medical schools: an approach. Interface Comun Saude Educ 2006; 10(19):93-102.

20. Rolando R. Emmanuel Levinas: para uma sociedade sem tiranias. Educ Soc 2001; 22(76):76-93.

21. Cecílio LCO. As Necessidades de Saúde como Conceito Estruturante na Luta pela Integralidade e Equidade na Atenção em Saúde. In: Mattos R, Pinheiro $\mathrm{R}$, organizadores. Os sentidos da integralidade na atenção e no cuidado à saúde. Rio de Janeiro: IMS UERJ, Abrasco; 2001. p.113-126.

22. Sucupira ACSL. Estrutura da consulta. In: Leite AJM, Caprara A, Coelho Filho JM, organizadores. Habilidades de comunicação com pacientes e famílias. São Paulo: Sarvier; 2007. p. 11-46.

23. Camargo Júnior KR. Um ensaio sobre a (in)definição de integralidade. In: Pinheiro R, Mattos RA, organizadores. Construção da integralidade: cotidiano, saberes e práticas em saúde. Rio de Janeiro: Instituto de Medicina Social (IMS), Universidade do Estado do Rio de Janeiro (UERJ), Abrasco; 2003. p. 35-44.

24. Baião MR, Deslandes SF. Gravidez e comportamento alimentar em gestantes de uma comunidade urbana de baixa renda no Município do Rio de Janeiro, Brasil. Cad Saude Publica. 2008; 24(11):2633-2642.

25. Saunders C, Accioly E, Costa, RSS, Lacerda EMA. Gestante adolescente. In: Accioly E, Saunders C, Lacerda EMA, organizadores. Nutrição em obstetrícia e pediatria. Rio de Janeiro: Cultura Médica; 2009. p. 149-172.

26. Martins A. Biopolítica: o poder médico e a autonomia do paciente em uma nova concepção de saúde. Interface Comun Saúde Educ 2004; 8(14):21-32.

27. Cascudo LC. História da Alimentação no Brasil. Belo Horizonte, Itatiaia: USP; 1983.

28. Coccaro LM. Da dissertação para o palco. Logos (Canoas RS) 2005; 16(2):39-47.

29. Menezes IHCF, Domingues MHMS. Principais mudanças corporais percebidas por gestantes adolescentes assistidas em serviços públicos de saúde de Goiânia. Rev Nutr 2004; 17(2):185-194.

30. Freire P. Pedagogia do Oprimido. São Paulo: Paz e Terra; 2005.

31. Deslandes SF. Análise do discurso oficial sobre a humanização da assistência hospitalar. Cien Saude Colet 2004; 9(1):7-14.

32. Schraiber LB. No encontro da técnica com a Ética: o exercício de julgar e decidir no cotidiano do trabalho em Medicina. Interface Comun Saúde Educ 1997; 1(1):123-140.

Apresentado em 06/04/2010

Aprovado em 13/06/2010

Versão final apresentada em 13/07/2010 